\title{
Liquefied Natural Gas as a Fuel in Inland Navigation: Barriers to Be Overcome on Rhine-Main-Danube
}

\author{
L. Simmer, S. Pfoser, and O. Schauer
}

\begin{abstract}
The shipping industry is committed to further reducing its emissions of air pollutants and greenhouse gases. Alternative fuels play a key role in achieving this goal. Liquefied Natural Gas (LNG) may offer an effective solution towards low-emission shipping. However, for the uptake of LNG in inland navigation, especially in the Danube region, there are numerous hindrances to be overcome, such as the lack of infrastructure or high investment costs. Therefore, the aim of this paper is a detailed analysis and assessment of the different aspects influencing LNG implementation in the inland waterway sector in the near future. An extensive literature research was carried out in a first step. Afterwards findings were subsequently discussed with experts and adapted. The results of this paper should point to the problem areas for the introduction of LNG as fuel with a view to making significant contribution for further implementation steps.
\end{abstract}

Index Terms-Alternative fuel, green logistics, inland navigation, $\mathbf{L N G}$.

\section{INTRODUCTION}

The transport sector is one of the most energy consuming and highest emission causing sectors in the EU-27 member countries, despite advances in transport technology and fuel economy. Under continuing business as usual these emissions are expected to grow by approximately $40 \%$ until 2030. In order to counteract this circumstance, the European Commission's Transport 2050 Strategy calls for breaking the oil dependence of transport and sets a target of $60 \%$ greenhouse gas emissions reduction from transport by 2050 [1].

Inland Waterway Transport (IWT) is actually known as an environmentally friendly mode of transport. With the introduction of increasingly stringent emission regulations for road transport, the corresponding emissions in road transport decreased greatly, which is not true for the inland waterway, since most engines did not meet any emission standard. In terms of major emissions such as nitrogen oxides and particulate, inland navigation stands to lose its comparative environmental advantage over the road transport [2]. Therefore the shipping industry is committed to further reducing its emissions of air pollutants and greenhouse gases. In order to reach these goals a big share of alternative fuels is required and hence the transport sector has become a key area for projects to develop and demonstrate new technologies.

Liquefied Natural Gas (LNG) may offer an effective solution and is also considered as an alternative fuel in the Commission Communication on a European alternative fuel

Manuscript received March 18, 2015; revised August 8, 2015.

L. Simmer, S. Pfoser, and O. Schauer are with the University of Applied Sciences Upper Austria, Wehrgrabengasse 1-3, A-4400 Steyr, Austria (e-mail: \{laura.simmer, sarah.pfoser, oliver.schauer\}@fh-steyr.at). strategy (COM (2013) 17) [3]. With the Directive 2014/94/EU of the European Parliament and the Council of 22 October 2014, a common framework for actions has been made, to establish an infrastructure for alternative fuels in the Union. In the course of this, some minimum requirements for the establishment of infrastructure for alternative fuels were stipulated, which must now be implemented by the Member States through their national strategic framework. Regarding LNG following provisions were determined: (1) Member States must ensure through their national strategic framework that a reasonable number of LNG stations are decorated in inland ports until 31 December 2030, thus LNG ships can freely move around within the Trans-European Transport Network (TEN-T) (2) Member States must designate those inland ports, which have to provide access to LNG fueling stations [4].

First joint public-private activities in the Netherlands can be considered as initial step and sound basis into exploring the markets for LNG use in the European inland navigation sector. Market access via the LNG import terminals in Zeebrugge and in Rotterdam together with the recent development of LNG becoming a commodity and being available also for small-scale LNG logistics have accelerated the market interest. While in North-Western Europe, LNG is already available in small-scale logistics, Central and Eastern Europe are still a white area. Therefore the activities on the Rhine are watched with great expectations from other regions, in particular from the Danube region [5].

To lend further impetus to the issue LNG, seven LNG projects received financial support within the framework of the TEN-T Call 2012. One of these projects is the "LNG Masterplan for the Rhine-Main-Danube" [6]. It is a multi-partner project consisting of 33 members (industry, research, interest groups) from 12 EU Member States. The project will provide a European strategy and pilot deployments for LNG as fuel for inland vessels as well as for LNG as cargo being transported on waterways and distributed via inland ports. The action consists of a set of feasibility studies, technical concepts, technical trials and pilot deployments of vessels and terminals [7]. Despite many activities and projects, the introduction of LNG in inland navigation is still hampered by a number of bottlenecks. Therefore the aim of this paper is to look at the different aspects influencing the LNG implementation in the inland waterway sector in the near future.

\section{Methodology}

As the purpose of this paper is to look at the different aspects influencing the LNG implementation in inland navigation in the near future, an extensive literature research 
was carried out in a first step. After the identification and definition of a number of aspects, they were grouped in categories: technical, logistics, financial, legal and environmental/social. After that, each aspect has been assessed based on three parameters; the likelihood, the consequence and the manageability (Fig. 1). Each of the aspects was given a qualitative judgment and a numerical value: low $(L=1)$, medium $(M=2)$ and high $(H=3)$. The product of the three judgments in numerical terms provides the ranking of aspects. The aspects, the judgments and the ranking were subsequently discussed with experts in a workshop and adapted. The workshop was held during the LNG Masterplan Consortium meeting in Galati, Romania on 27 May 2014.

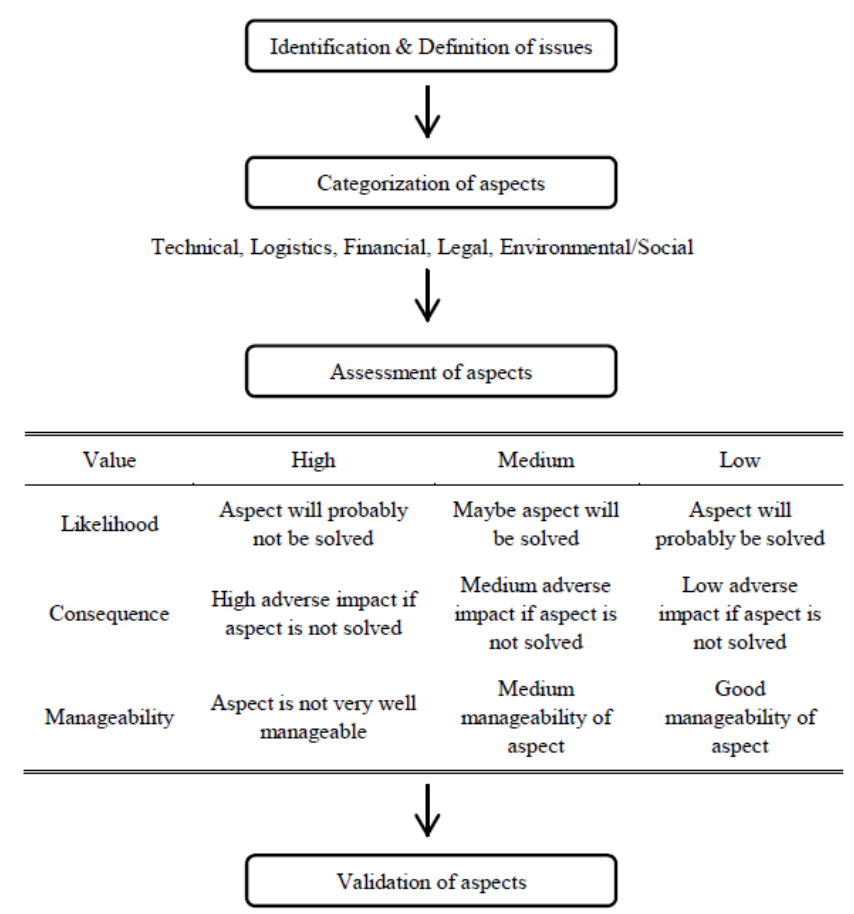

Fig. 1. Description of the methodology.

\section{RESULTS AND DISCUSSION}

Identified aspects influencing the LNG implementation in the inland waterway sector in the near future are summarized in Table I. The study suggests that most of the aspects influencing the LNG implementation in the inland waterway are in the category financial, followed by the categories technical and legal. Just one aspect belongs to the category environmental and no aspect is in the category logistic. Capital investment is the aspect which most influencing LNG implementation in inland navigation in the near future, but also the aspects retrofitting (push boat), LNG costs compared to other fuels and return on investment are important points for the introduction of LNG. Single aspects are explained in more detail below.

\section{A. Space Requirement for Tank (New Build Vessel)}

Space-consuming LNG fuel tanks affect ship productivity and freight earnings. LNG has a 1.8 times larger volume than diesel oil, and if one includes the whole system of LNG engine and cylindrical-shaped fuel tank onboard, the space needed is even three to four times larger than the conventional oil system [8]. The likelihood that this aspect is not solved has been judged high, since it seems not possible to reduce the tank size technically or economically at a large extend. The consequence is low, because fuel tank capacity can be expected to be considered in the new building, for example it is possible to place the LNG tank vertically in the heart of the vessel (centre of gravity) in new push boats. As in [9] the feasibility study considered the new building of a $3 \times 1200$ horsepower Push Boat with LNG propulsion as good. But it shall be noted that there could be a loss of payload for bulk cargo motor vessels (e.g. transport of coal, ores sand/gravel). In a project about the conversion for the inland water vessel MS Otrate, a dry cargo ship, the cargo volume was $1,350 \mathrm{~m}$ before the conversion, and 1,232 $\mathrm{m}$ after the conversion [10]. Moreover the additional weight of the LNG tank can decrease the net payload of the vessel. With several LNG bunker opportunities along waterways in Europe, there will be a limited need for a large LNG storage tank. Therefore it is assumed that a standard ISO-20 foot tank container can be sufficient. The aspect is not very well manageable. Maybe with an increase in the tank infrastructure density smaller tanks could be used which could, if appropriate, improve the application potential for smaller or existing vessels [11].

TABLE I: SUMMARIZED RESULTS OF THE ANALYSIS FOR THE INLAND

\begin{tabular}{|c|c|c|c|c|c|}
\hline \multirow[b]{2}{*}{ Aspects } & \multirow[b]{2}{*}{ Category } & \multicolumn{4}{|c|}{ Assessment 2020} \\
\hline & & $\begin{array}{l}\text { Likeli- } \\
\text { hood }\end{array}$ & $\begin{array}{l}\text { Conse- } \\
\text { quence }\end{array}$ & $\begin{array}{l}\text { Manage- } \\
\text { able }\end{array}$ & Risk \\
\hline $\begin{array}{l}\text { Space requirement for } \\
\text { tank (new build vessel) }\end{array}$ & $\mathrm{T}, \mathrm{F}$ & $\mathrm{H}$ & $\mathrm{L}$ & $\mathrm{H}$ & 9 \\
\hline Retrofitting (push boat) & $\mathrm{T}, \mathrm{F}$ & $\mathrm{H}$ & M & $\mathrm{H}$ & 18 \\
\hline $\begin{array}{l}\text { Retrofitting } \\
\text { (self-propelled vessel) }\end{array}$ & $\mathrm{T}, \mathrm{F}$ & M & M & $\mathrm{H}$ & 12 \\
\hline $\begin{array}{l}\text { Efficiency of gas engines } \\
\text { under part load }\end{array}$ & $\mathrm{T}$ & $\mathrm{L}$ & $\mathrm{L}$ & $\mathrm{L}$ & 1 \\
\hline $\begin{array}{l}\text { Quality requirements for } \\
\text { LNG }\end{array}$ & $\mathrm{T}$ & $\mathrm{L}$ & $\mathrm{L}$ & $\mathrm{L}$ & 1 \\
\hline $\begin{array}{l}\text { LNG bunkering } \\
\text { infrastructure }\end{array}$ & $\mathrm{F}$ & M & $\mathrm{H}$ & M & 12 \\
\hline $\begin{array}{l}\text { LNG cost compared to } \\
\text { other fuels }\end{array}$ & F & M & $\mathrm{H}$ & $\mathrm{H}$ & 18 \\
\hline Capital investments & $\mathrm{F}$ & $\mathrm{H}$ & $\mathrm{H}$ & $\mathrm{H}$ & 27 \\
\hline Return on investment & $\mathrm{F}$ & M & $\mathrm{H}$ & $\mathrm{H}$ & 18 \\
\hline Regulation on bunkering & Le & $\mathrm{L}$ & $\mathrm{H}$ & $\mathrm{H}$ & 9 \\
\hline $\begin{array}{l}\text { Regulation gas fuelled } \\
\text { vessels }\end{array}$ & $\mathrm{Le}$ & $\mathrm{L}$ & $\mathrm{H}$ & $\mathrm{H}$ & 9 \\
\hline $\begin{array}{l}\text { Crew training gas } \\
\text { tanker/gas fuelled vessel }\end{array}$ & $\mathrm{Le}$ & $\mathrm{L}$ & $\mathrm{L}$ & M & 3 \\
\hline Methane slip & $\mathrm{T}, \mathrm{E}$ & $\mathrm{M}$ & M & $\mathrm{H}$ & 12 \\
\hline
\end{tabular}

\section{B. Retrofitting (Push Boat)}

Only part of the existing ship fleet is suitable for an LNG retrofit. For some vessels it is not possible to install an LNG tank due to space restrictions [12]. So, depending on vessel type and operation a retrofit can be feasible, but it is not expected to become a mainstream activity. The other problem is that the cost for retrofitting is higher than for new building [13]. It is assumed that existing push boats cannot be adapted to LNG, because they do not have room to place an LNG tank. As they use a lot of fuel these boats need a high storage capacity. The key problem here is to find space for the fuel tank as for reasons of stability it has to be placed in the gravitational centre of the vessel where the engine room is already situated [14]. The likelihood that this aspect is not solved has been judged high, since gas as fuel will be mostly driven by new-building activity. Moreover as in [9] the retrofitting of a $2 \times 600$ horsepower and a $2 \times 1600$ horsepower Push Boat were considered as not suitable. The consequence 
is medium, because other vessels can be retrofitted and also new ships and also new build push boats can use LNG. The ability to manage this aspect is not very well, because of the severe technical barriers.

\section{Retrofitting (Self-propelled Vessel)}

As only part of the existing ship fleet is suitable for an LNG retrofit, the retrofitting should be considered individually for each vessel. The retrofit will depend on the age and the length of the vessel and also according to which class the ship is built. Beneficial for the accommodation of the tanks are tank- and container ships, although the additional weight of the LNG tank will decrease the net payload of the vessel. The other problem is that the cost for retrofitting is higher than for new building [13]. The likelihood that this aspect is not solved has been judged medium, because in [9] a retrofitting of a self-propelled barge could be considered. In another project the conversion for the inland water vessel MS Otrate, a dry cargo ship, was examined. The outcome of this project was that the technology and logistics for a conversion already exists and in this case it is also economically feasible to do a conversion [10]. The consequence is medium, because some vessels are suitable for a retrofit and also new vessels will join the market The aspect is not very well manageable, since it will depend on financial (cost for retrofitting, LNG price) and technical concerns (tank space, safety issues).

\section{Efficiency of Gas Engines under Part Load}

Engine efficiencies for LNG-fuelled marine engines are good. They can be sorted into three groups: Spark Ignited Lean-Burn engines (LBSI) and Dual-Fuel engines (DF); high pressure gas injection (300-350 bar) and low pressure gas injection. The high pressure gas injection engines are not used in inland waterway ships. So in Lean Burn Spark Ignited engines (LBSI) and in low pressure gas injection engines the thermal efficiency is very high at max load and low at part load [15]. The likelihood that this aspect is not solved has been judged low, because with gas-electric ship propulsion, like installed in the vessels "Greenstream" and "Greenrhine", there is no problem with the efficiency under part load [11]. The consequence is low and the ability to manage this aspect is good, because of the choice to use gas-electric ship propulsion.

\section{E. Quality Requirements for $L N G$}

The quality of LNG as a fuel in an open bunker market may differ every time the ship is bunkered, and some robustness is therefore required. The methane number is the parameter used to quantify knocking tendency of a gas and is especially relevant when natural gas is used as engine fuel. It is usually admitted that knocking problems are avoided for installations with a methane number higher than 75-80. For cogeneration applications, engine characteristics are specified for gases with a methane number higher than 65-75. When methane number is between 55 and 65 , taking measures to prevent engine knocking is recommended. For a methane number lower than 55, leaving engine out of service is the best option [15], [16]. The likelihood that this aspect is not solved has been judged low, because there could be an agreement with the supplier that the LNG has to be delivered at a certain quality. Moreover since gas engines are becoming increasingly popular, also the technology continues to move forward and LNG treatment technologies are in constant evolution. The consequence is low and there is a good manageability of this aspect.

\section{F. LNG Bunkering Infrastructure}

A critical challenge to the development of LNG as ship fuel is the current lack of established bunkering infrastructure and distribution networks for delivering LNG to inland ships. With the Directive 2014/94/EU Member States have to provide access to LNG fueling stations until 31 December 2030, but according to the Observatory of European Inland Navigation there are no LNG implementation projects for bunkering on the Danube, except the LNG Masterplan (Shore-to-ship bunkering in the Port of Ruse).

However, on the Rhine four bunker stations are already completed. These are the truck-to-ship bunkering in the Port of Rotterdam, in the Port of Amsterdam, in the Port of Mannheim and in the Port of Antwerp. Other projects, like the ship-to-ship bunkering in the Port of Rotterdam, are also running respectively are in planning [17].

The likelihood that this aspect is not solved has been judged medium, since expensive investments are necessary. This 'chicken-and-egg' dilemma can best be mitigated through government involvement. The approach for such involvement can be subsidies, funding or reduced taxes etc. The EU has started to develop financial instruments to support the introduction of LNG bunkering infrastructure, such as the funding from the Trans-European Transport Network [8]. The consequence is very high, because if there is no bunkering infrastructure, nobody will invest in a vessel. The ability to manage this aspect is medium. As written, subsidies and funding are good possibilities to overcome this barrier, however, large amounts of money are needed.

\section{G. LNG Cost Compared to Other Fuels}

From an end user's perspective, it is not the level of the LNG price which is the most important driver but the price relative to alternatives, i.e. diesel for truck owners or marine gas oil (MGO) or heavy fuel oil (HFO) for ships. The retail price of LNG for end users is not equal to the price at which suppliers import LNG. This price is mainly related to the costs of winning, liquefaction and large scale transportation. The specific cost of small scale distribution should be added to that price (e.g. cost of transport to stations, bunker solutions, refueling stations). For transport companies, fuel costs represent a significant part of annual transportation costs. Fuel costs for an inland ship easily represent more than $40 \%$ of total annual costs. The prices of different fuels show a wide range for the shipping industry. For instance, the prices for different products (Rotterdam quotations) on 1 March 2013 were as follows: MDO (middle distillate) at 894 USD/MT (US dollars per mega ton), LSFO (low sulphur fuel oil) at $632 \mathrm{USD} / \mathrm{MT}$, HSFO (high sulphur fuel oil) at 602 USD/MT and LNG at 467 USD/MT. But the oil product prices are delivered at free on board prices, while the LNG price is a hub-based price. Once we add the additional costs for logistics to derive a comparable retail price, it would be about $€ 50 / \mathrm{MWh}$, which translates into a price of 602 USD/MT, or very similar to high sulphur fuel oil prices. In landlocked Europe LNG might be even more expensive on the basis of additional transportation costs [12]. The 
likelihood that this aspect is not solved has been judged medium. Some analysts expect an increase in the price of low-sulphur diesel when new emission regulations in Sulphur Emission Control Areas are enforced and the demand for low-sulphur diesel increases. In conclusion, it is not unlikely that in the first coming years, natural gas and LNG prices could rise a bit, both in absolute and relative (to diesel) terms. But when more LNG supplies come online, price pressure is expected to drop, allowing LNG prices to go down, at least relative to diesel prices. Although there are significant uncertainties in this area, there are convincing arguments that oil price risks are skewed to the upside, while gas price risks are skewed to the downside. The consequence is high, because if LNG is more expensive or equal to marine gas oil (MGO) or heavy fuel oil (HFO), there is no incentive for ship owners to change to LNG. The aspect is not very well manageable, since nobody can influence world market prices. Only the government can influence prices a little bit through taxes, but the shipping sector is not subject to any tax. This is based on the so-called Mannheim pact which prescribes no tax for all European waterways connected to the Rhine. As this is a European agreement, no changes are expected in the short to medium term [12].

\section{H. Capital Investments}

Machinery-related investment costs for an inland LNG ship are more expensive than the machinery-related investment costs for an inland marine gas oil ship. This is partly driven by higher material costs (the LNG tank is expensive), higher safety restrictions that must be taken into account and by the low number of vehicles currently produced. The likelihood that this aspect is not solved in a few years has been judged high, since driven by the current economic situation, companies are reluctant to make those large investments, especially as positive returns of the LNG business case have not yet been proved in practice [12]. According to [14] the LNG technology could be economically feasible for new vessels already sailing 5.000 engine hours per year as the payback time would be around five years, based on a $20 \%$ price advantage for LNG fuel compared to diesel fuel. In particular, for the new larger vessels that operate on a $24 / 7$ basis, investments in LNG would then be attractive from an economic viewpoint, irrespective of any environmental benefits. The current LNG dual fuel solutions with $80 \% \mathrm{LNG}$ and $20 \%$ diesel as a fuel mix are expected to result in fuel consumption cost savings of at least $20 \%$ in comparison with conventional diesel engines. This generates benefits that compensate the higher investments in LNG technology and in particular, investments in the fuel tanks and the engine. Moreover, further developments are expected in the field of engines using LNG fuel. These developments will further reduce fuel costs, such as higher shares of LNG $(95 \%$ LNG, $5 \%$ Diesel fuel mix) and also mono-fuel LNG engines in gas-electric configurations. The time horizon that needs to be bridged is however, an important aspect for deciding on the type of technology. The assessments made in this study take into account a time horizon of 20 years in order to derive the best option from an economical viewpoint [14]. The consequence is also high, because no investments are made. The ability to manage this aspect is not very well. Particularly the shipping sector faces financial difficulties due to declining demand, overcapacity and increasing competition. For those reasons, banks are reluctant to provide financial support. Funding could be a possibility to overcome this barrier.

\section{Return on Investment}

The level of fuel consumption is crucial as this influences the payback time needed to recoup high investment cost. Payback times (for extra investment costs) for dual-fuel propulsion are in the range of 4 to $>10$ years depending on running hours and average power at a LNG price of $80 \%$ of gasoil [18]. The likelihood that this aspect (long payback time) is not solved has been judged medium, as the return on investment depends on the one hand on capital investment costs and on the other hand on fuel cost savings. Small ships with less operating hours have less fuel cost savings than Push Boats with very high fuel costs [19], [20]. The consequence is also high because no investments are made, if payback times are too long. The aspect is not very well manageable, since it is difficult to influence fuel costs and capital investment costs.

\section{J. Regulations on Bunkering}

LNG bunkering is not regulated yet. For example there are no regulations for following points: definition of the $\mathrm{LNG}$ bunkering process, LNG bunkering procedures, LNG ship to delivering facility interfaces, LNG bunker port operations, LNG bunkering safety distances, LNG bunkering risk assessment and risk acceptance criteria, LNG bunkering during loading/unloading and passenger embarking/disembarking, LNG bunker related emergency plans, LNG fuel sampling, LNG fuel measurement and environmental requirements [12]. The likelihood that this aspect is not solved has been judged low, because many guidelines and codes are under development. For example on 9 March 2014 the new Municipal Police Regulations, Port Guidelines and associated forms came into force. For the first time ever the regulations include specific procedures for LNG bunkering. With these procedures the Port Authority aims to ensure that bunkering with LNG is carried out as safely as possible [21]. The consequence is high because investments without regulation are difficult. The ability to manage this aspect is not very well, because it is difficult to influence official procedures.

\section{K. Regulation Gas Fuelled Vessels}

The use of LNG as fuel for inland vessels is not regulated yet. The inland shipping legislations (International Carriage of Dangerous Goods by Inland Waterways (ADN), Rhine Vessel Inspection Regulations (RVIR) and European directive 2006/87/EG) contain specific information about the use of fuel in a shipping engine. The use of fuel with a flashpoint below $55^{\circ} \mathrm{C}$ is not allowed. The flashpoint of LNG is around $-181{ }^{\circ} \mathrm{C}$, which means that the current legislation does not allow the use of LNG as a fuel for inland shipping. The member states of the European Union transformed the European directive in country specific shipping rules, implying that LNG as a fuel for inland shipping cannot be used in any of the member states [22].

The likelihood that this aspect is not solved has been judged low, because to close this regulatory gap, the EU authority has started to establish a specific permit process for LNG-powered inland vessels and later may develop appendices under the existing regulatory framework [8]. 
Finalizing date and content of the amendments are not foreseeable, but maybe the year 2015 [23]. The consequence is high, because the fact that there is currently no legal framework for LNG-powered ships is an obstacle to more rapid spread of the use of LNG as a fuel. Currently the lack of legal framework acts as investment barrier for the industry [24]. The aspect is not very well manageable, because it is difficult to influence official procedures.

\section{Crew Training Gas Tanker/Gas Fuelled Vessel}

The transport of LNG by inland tanker is not regulated, just as the use of LNG as fuel for inland vessels is not regulated. A very significant development is that the Society of International Gas Tanker and Terminal Operators (SIGTTO) has created a new organization - the Society for Gas as a Marine Fuel (SGMF) - that is focused on gas-fuelled shipping. That will greatly contribute to the standards of crew and people involved in handling gas safely [13]. The likelihood that this aspect is not solved has been judged low, because first applications and rule development initiatives recently started. Finalizing date and content of the amendments are not foreseeable [23]. The consequence is low. The ability to manage this aspect is medium.

\section{Methane Slip}

The bandwidth of today's gas engines is great. Accordingly, the bandwidth is in the methane slip. Today's natural gas engines often cannot utilize methane completely [25]. To maximize the reduction in greenhouse gas emissions when using LNG as a fuel, the methane emission of engines needs to be minimized. As a result, an emission limit needs to be in place to prevent an increase of the climate change impact as a result of methane emissions. The vessel "MTS Argonon", running on dual-fuel LNG, has a methane slip catalyst on board in order to eliminate this problem. There are however, questions on the durability of such devices. The need to renew these devices can be considered a cost subject [14]. The likelihood that this aspect is not solved has been judged medium, because technically it is very ornate to ensure no methane slip, and it is also very costly. The consequence is medium, because with methane slip the environmental friendliness is going back. The ability to manage this aspect is not very well.

\section{SUMMARY AND CONCLUSION}

The present work provides a look at the different aspects influencing the LNG implementation in the inland waterway sector in the near future. After a sound literature research, an expert workshop was held to review the aspects and the judgments and prove evidence.

Altogether, this study suggests that most of the aspects influencing the LNG implementation in the inland waterway are in the category financial, followed by the categories technical and legal. Just one aspect belongs to the category environmental and no aspect is in the category logistic.

Capital investment is the aspect which is most influencing LNG implementation in inland navigation in the near future, but also the aspects retrofitting (push boat), LNG costs compared to other fuels and return on investments are important points for the introduction of LNG. LNG bunkering infrastructure, retrofitting (self-propelled vessel) and methane slip have to be considered too. Aspects like the efficiency of gas engines under part load, quality requirements for LNG or crew training are less important.

As the introduction of LNG as fuel is a complex transition process, it requires actions in various fields. The topic LNG continues to provide sufficient space for research and implementation projects and a number of open issues must be clarified in the future. But with LNG, the inland navigation sector can increase its competitive position on the transport market and will continue as the most environmentally friendly transport mode.

\section{REFERENCES}

[1] European Commission, "A roadmap for moving to a competitive low carbon economy in 2050," Brussels, 2011.

[2] G. Pauli and J. Schweighofer, "Exhaust emissions on inland waterways," presented at 29th Duisburg Colloquium on Shipbuilding and Marine Engineering, University of Duisburg-Essen, Institute of Ship Technology, Ocean Engineering and Transport Systems, June 12-13, 2008

[3] European Commission, "Clean power for transport: A European alternative fuels strategy," Brussels, 2013.

[4] Directive of the EU, "Directive 2014/94/EU of the European parliament and of the council of 22 October 2014 on the deployment of alternative fuels infrastructure," Official Journal of the European Union, p. L 307/1, 2014.

[5] O. Schauer, L. M. Putz, and F. Starkl, "The European LNG masterplan: Introducing LNG as fuel and cargo on the Rhine-Main-Danube," in Proc. the 8th International Symposium on Environmentally Conscious Design and Inverse Manufacturing, Jeju Island, Südkorea, 2013.

[6] Natural and Bio Gas Vehicle Association Europe. (2013). European Commission selects 7 LNG projects as winners in TEN-T call 2012. Available:

http://www.ngvaeurope.eu/european-commission-selects-7-lng-projec ts-as-winners-in-ten-t-call-2012

[7] M. Seitz, "LNG as fuel for inland vessels and as a cargo on the rhine-main-danube," presented at Small Scale LNG Forum, Pro Danube International, Rotterdam, Nov. 6-8, 2013

[8] S. Wang and T. Notteboom, "LNG as a ship fuel: Perspectives and challenges," Port Technology International, vol. 60, pp. 15-17, Nov. 2013.

[9] I. Ovidiu, "New concept — Dual fuel pusher for danube," presented at Wärtsilä seminar, Galati, Romania, April 9, 2014.

[10] J. A. Tarazona, M. Bergfast, M. Schwarzer, and S. Sezen, "Conversion of an inland water vessel to LNG fueled operation," University of Applied Sciences Kiel, Germany, 2012.

[11] R. Wurster, W. Weindorf, W. Zittel, P. Schmidt, C. Heidt, U. Lambrecht et al., "LNG as a fuel alternative for the propulsion of ships and heavy duty vehicles," German Aerospace Center (DLR), Munich/Ottobrunn, Heidelberg, Berlin, 2014.

[12] PwC, "Economic impacts of LNG in the transport sector," May 2013.

[13] Gastech News. (2014). CoTE Focus: LNG fuel technology. [Online]. Available: http://www.gastechnews.com/lng/cote-focus-lng-fuel-technology/

[14] European Commission's Directorate-General for Transport, "Contribution to impact assessment of measures for reducing emissions of inland navigation," Zoetermeer, 2013.

[15] D. Stenersen, "Gas Fuelled ships. LNG-fuelled engines and fuel systems for medium- Speed engines in maritime applications," presented at GTS Technical Seminar Series, Norway, Sept. 28, 2011.

[16] A. M. Gutierrez, "New thermal conductivity microsensor to measure the methane number of natural gas," in Proc. the 23rd World Gas Conference, June 2006, vol. 5, pp. 2655-2666.

[17] C. Hurbourque. (2014). Observatory of European inland navigation. Central Commission for the Navigation of the Rhine (CCNR). [Online]. Available: http://www.inland-navigation.org

[18] B. Kruyt, "ECO ${ }_{2}$ inland vessel project," presented at LNG Conference Leer, 2013.

[19] K. Baumann, B. Kruyt, and L. Van der Burg, "LNG-activities in Dutch-German cooperation," presented at Small Scale LNG Forum, MARIKO GmbH, Fleming Europe, Rotterdam, 2013.

[20] H. van der Werf, "LNG as fuel in inland navigation," presented at LNG Conference Leer, Mar. 5, 2013 
[21] Port of Antwerp. (2014). Port of Antwerp publishes procedures for LNG bunkering. [Online]. Available: http://www.portofantwerp.com/en/news/port-antwerp-publishes-proce dures-lng-bunkering

[22] DNV Belgium, "Modalities for the provisioning of LNG as shipping fuel in Flemish ports: Part II: Legal \& regulatory," Flemish Department of Mobility and Public Works, Belgium, July 2012.

[23] G. Lloyd, "Study on standards and rules for bunkering of gas-fuelled ships," European Maritime Safety Agency (EMSA), Department Machinery Systems, Hamburg, Feb. 15, 2013.

[24] MARIKO GmbH, "LNG initiative Northwest and MARIKO — legal framework for the use of LNG as fuel," Nordic Market, Mar. 27, 2014.

[25] F. Meyer, "Methane losses - using LNG as fuel for otto-gas and dual-fuel engines on ships," presented at LNG-Workshop, Leer, 2013.

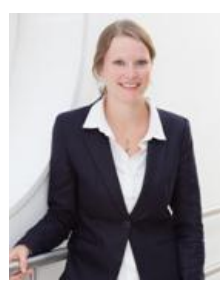

Laura Simmer was born in Austria, on January 15, 1988. She obtained her M.Sc. degree in environment and bio-resources management at the University of Natural Resources and Life Science in Vienna, Austria. She is currently a research associate at the University of Applied Sciences in Upper Austria. Her research interest focuses on sustainable transport systems.

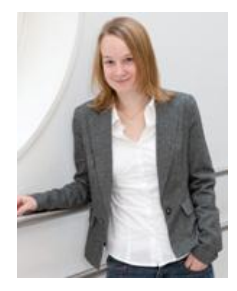

Sarah Pfoser was born in Austria, on August 30, 1989. She obtained her master's degree in management and applied economics at the Johannes Kepler University in Linz, Austria. Since 2013, she has been a research associate at the University of Applied Sciences in Upper Austria. She has work experience in project management and qualitative research activities. Her current research focuses on alternative fuels and sustainable freight transport concepts.

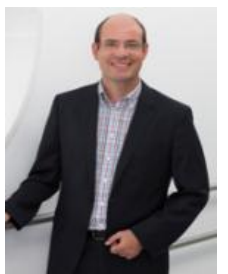

Oliver Schauer was born in Austria, on March 24, 1974. He obtained his diploma in law (Mag. Iur.) at the Faculty of Law, Johannes Kepler University in Linz in 1997. In 2001, he received his doctorate in law (Dr. iur.), graduated with distinction at the Faculty of Law, Johannes Kepler University, Linz. In 2005 he finished his executive master of business administration (MBA) at LIMAK Johannes Kepler University Business School, Linz. Mr. Schauer has work experience as a lecturer (secondary profession) at the Johannes Kepler University, Linz and at the University of Applied Sciences Upper Austria. He also was the head of Personnel, Legal \& Risk Management Department and member of the Executive Management at Schachinger Holding Transport \& Logistik GmbH. Since 2012 he has been a professor in mobility and transport management at the University of Applied Sciences Upper Austria. 